DOI: $10.19195 / 2084-5065.49 .3$

\title{
Using gelatin dactyloscopic foils and computer program Adobe Photoshop in expert analysis of crossed lines
}

\author{
MirosLAV BuSARČEVIĆ
}

Serbia

\section{BRANISLAV SIMONOVIĆ}

ORCID: 0000-0002-3445-0320

Faculty of Law, University of Kragujevac, Serbia

\section{Introduction}

Expert analysis of documents (and manuscripts) represents a subject which is rarely the topic of scientific and professional papers written by authors from South-East Europe. There is a notable disproportion between the fact that this topic is often neglected in written papers in the field of criminalistics on the one hand, and its relevance on the other, since expert analysis of documents and handwriting is quite frequent in court practice. However, in Serbia, certain monographs on the expert analysis of handwriting published many years ago are still highly esteemed (e.g., Simonović, 1956; Aleksić, 1996). The area of expert analysis of the documents requires a wide range of knowledge, application of various methods in the fields of traceology, physics and chemistry, as well as skills in handling and using different kinds of instruments, apparatus and tools to conduct the analysis. One of the especially complex problems in this field is the expert analysis of crossed lines. 
In the practice of expert analysis of crossed lines several groups of different methods were and are still used, some of which are regarded as destructive (invasive), while others are considered to be non-destructive methods. According to some authors the methods of crossed lines expert analysis can be divided into morphological analyses of the lines and physico-chemical analyses of the ink (e Brito, Martins, Braz, Chaves, Braga, \& Pimentel, 2017).

In the literature from different periods, various methods of expert analysis of crossed lines in the documents are described. For example, the optical methods of the analysis with the use of classic microscopes (Godown, 1963; Strach, 1978); the use of scanning electronic microscopy SEM (Oron \& Tamir, 1979; Waeschle, 1979); lifting techniques (Koons, 1985; Jasuja, Singla, \& Chattopadhyay, 1987; Singla, Jasuja, \& Kaur, 1994); the use of ESDA apparatus (Giles, 1993; Radley, 1995; Daéid, Whitehead, \& Allen, 2008); the use of spectroscopic methods (Bojko, Roux, \& Reedy, 2008; Vaid, Rana, \& Dhawan, 2011); the method of chemical analysis of ink, e.g., chromatic luminescence methods (INTERPOL's Counterfeit Currency and Security Documents Branch [CCSD] and International Academy of Experts in Handwriting and Documents [AIEED] Research Project "Physicalchemical Study of Crossed Lines Intersection", 2017), etc.

However, regardless of the applied methods, the literature highlights certain limits of crossed lines analysis (Day, Ellen, \& Davies, 2005; e Brito et al., 2017), so this subject is always open and relevant despite the invested effort and expensive state-of-the-art equipment which is used.

In Serbian and former Yugoslavian professional literature, the authors (Maksimović, Bošković, \& Todorić, 1990, pp. 419-422) have described the method of print lifting of crossed lines using white gelatin dactyloscopic foils, under the light pressure of a press for a couple of minutes as an invasive method. After the lifting of dactyloscopic foil in this method, reflection of crossed lines can be observed and the line which has been made last is uninterrupted and intersects the line which was made first. The mentioned authors indicate that this method is successful when the used writing material adheres more easily. They also indicate that in some cases, especially when it comes to ballpoint pen ink, better results are obtained if the dactyloscopic foil is lightly moistured with acetone or methanol which dissolve the ink and, therefore it is better adhered on the foil. 
However, practice has shown that the results obtained by the application of this method are rarely satisfactory. This is due to the fact that light pressure of a press for a couple of minutes is not enough for obtaining useful, barely visible prints on the foil, even when it comes to recentlycreated documents in which crossed lines are made with ballpoint pen ink, which is thought to be best reflected on the dactyloscopic foil. Apart from that, it has been proved that it is highly risky to pour some acetone or methanol on the foil before putting it under the press. The experiments have shown that acetone and methanol, apart from ballpoint pen ink, also dissolve the adhesive layer of gelatin dactyloscopic foil, and the adhesive in the paper itself as well. Because of this, the adhesive layer of the foil adheres with the surface of the paper, in some cases so tightly ${ }^{1}$ that the foil cannot be separated from the paper without serious damage (ripping).

On the other hand, experiments with the strong pressure of the press which lasted for 30 minutes did not give better results, and there were difficulties with the separation of the adhesive layer of the foil from the paper and the paper fibers were often visible on the foil, while the crossed lines which were hardly visible were deformed on the lifted print.

\section{The overview of M. Busarčević's method: The use of gelatin dactyloscopic foils and Adobe Photoshop computer program in the expert analysis of crossed lines}

In his search for a solution M. Busarčević has, during his long-lasting career, come to the conclusion that the best results in lifting prints with gelatin dactyloscopic foils are obtained when the pieces of foil set over the crossed lines with their adhesive layer are exposed to consecutive hammer blows of light to medium intensity, rather than constant pressure of the press. This can be obtained by executing several consecutive blows of the same intensity (7-8) with the blunt or straight end of the hammer head of a $300 \mathrm{~g}$ heavy hammer. Blows are conducted under a vertical angle, directly on the piece of dactyloscopic foil which is placed over the crossed lines in the document with its adhesive layer

1 When undiluted acetone was used. 
and placed on a flat and smooth surface. However, this surface should not be too hard because of the risk of damaging (ripping) the document by heavy hammer blows. This can be avoided if a thick, flat piece of rubber or 2-3 layers of flat cardboard are placed on the surface under the document. In this way, the risk of damaging the document by hammer blows will be significantly decreased, and, at the same time, will enable the complete adhesion of the elastic adhesive layer of the foil to the ink in crossed lines, on the surface, as well as inside the paper.

Under the pressure of each hammer blow, the elastic and adhesive layer of the foil instantly compresses and expands, and then it tends to go back to its previous state. This is why the intensity of the blows should be kept within the limits of the adhesive layer's elasticity, or, at least, exceed those limits to the smallest possible extent. Thus, greater deformities of the adhesive layer which could reflect on the print of the crossed lines would be avoided. This is why hammer blows should be of a light intensity, and only in cases when the visualized print of crossed lines is not of a satisfactory quality should the procedure be repeated with stronger blows. Even if the intensity of the hammer blows is greater than necessary, they will not make any kind of deformities in the text or on the crossed lines which are covered with the piece of dactyloscopic foil in the document. The only effect which can occur is a certain deformity of crossed lines' print on dactyloscopic foil due to exceeding the limits of its adhesive layer's elasticity. However, this is the effect which is almost always present and does not affect the further processing of prints.

Adhesive forces of the adhesive layer of the dactyloscopic foil are much weaker than those of the adhesive which bonds the fibers of the paper itself, and this is why, in most cases, there will be no lifting of them with the gelatin dactyloscopic foils. Before the lifting of crossed lines this should be checked with so-called blank determination. As a rule the blank determination is conducted on a small surface in one of the corners of the document paper, outside its content, and the hammer blows should be stronger than those to which the piece of the foil will be exposed during the print lifting of crossed lines. If the fibers of the paper remain on the adhesive layer of the dactyloscopic foil during this procedure, then there is a risk that the document will be damaged during the application of this method. This is especially in cases when the document paper is 
old and yellow and/or shabby at the point where lines are intersected (for example because of the folding).

During the print lifting, apart from the adhesion forces of the dactyloscopic foil, moisture in the adhesive layer of the foil plays an important role, since it is partially squeezed out, and it moistens the ink of the crossed lines to some extent, which can help its adhesion to the adhesive layer of the dactyloscopic foil. This may be the reason for obtaining a better reflection of crossed lines through the repeated process with dactyloscopic foil in old documents.

In an extreme case, in experiments in which crossed lines print is made with aniline ink ${ }^{2}$ and lifted immediately after the lines are created on the paper, before the ink starts to dry, the print might show a false image of crossed lines in which the lower line intersects the upper line, even though that is not the case. Fortunately, this is not the case with documents which undergo expert analysis. It should also be taken into consideration that the constant repetition of lifting layers of the same crossed lines leads to visible changes seen as gradual fading and disappearing of the lines.

White gelatin dactyloscopic foils are used for lifting the prints in the described way. However, depending on the colour of the paper and crossed lines in it, black foils can be used equally successfully. Only small pieces of dactyloscopic foil should be used. Their dimensions are determined according to the area of the documents from which crossed lines prints are lifted (most often $3-5 \mathrm{~cm}^{2}$ ).

Obtained prints of crossed lines are in most cases, slightly or barely visible and it is necessary to work on them additionaly - to use the visualization function in Adobe Photoshop ${ }^{3}$ until the optimal visibility is obtained. With this aim the lifted print is previously scanned in high resolution, ${ }^{4}$ in tif. or jpg. format, and then visualization in the computer program is performed. When the pieces of white dactyloscopic foil are used it is enough to darken the lifted print, so that it can become clearly visible which line intersects the others. However, it should be taken into consideration that darkening of the scanned print on the white foil changes the colour of the foil and, thus, the colour of reflected lines.

2 Used to fill ballpoint pens, fountain pens, seals, etc.

3 Most often by using the following options of the program: Image-AdjustmentsLevels, Image-Adjustments-Brightness/Contrast and Filter-Sharpen-Unsharp Mask.

4 1.200-2.400 pix/inch.

Nowa Kodyfikacja Prawa Karnego 49, 2018

(C) for this edition by CNS 
The print on the dactyloscopic foil always represents the negative of crossed lines which is an isomer ${ }^{5}$ of their image on the paper of the document. Because of this and in order to avoid any doubts during the simultaneous display of crossed lines print and their real appearance in the document, the visualized prints should be transformed from negative into positive by being rotated ${ }^{6}$ for $180^{\circ}$ in Adobe Photoshop.

Although this method of analysis is invasive and destructive, its application does not cause changes in crossed lines' image visible to the naked eye or even under an optical magnifying glass, and that is because a microscopically thin layer of material is lifted from the crossed lines on the paper which is measured in micrometres. ${ }^{7}$ This enables repetition of print lifting on the same crossed lines in the document without visible changes in their appearance. However, it should be noted that there are differences among different kinds of substances with which crossed lines are made (inks, toners, etc.) in their susceptibility to dactyloscopic foil lifting. Apart from the kind of substance this will depend on other factors such as the age of the document and the influence of different external factors to which the document was exposed, primarily humidity and temperature. So, there are cases when some of the crossed lines in the document are susceptible to lifting, and the others are not.

It is well-known that every piece of paper becomes yellow after a certain period of time, even in a dry room at normal temperature. The reason for this lies in the degradation of the adhesive which connects the fibers of the paper under the influence of infra-red (hot) rays, which is, to a greater or lesser extent, followed by degradation of the substance with which the crossed lines on the paper are made. But different materials and substances used for writing are not equally susceptible to this process, and because of that, the speed and manifestation of their degradation primarily depend on the material and the substance.

The experience has shown that there is no rigid rule to grade the level of adhesion of substances to dactyloscopic foil. It is often stated that the ballpoint pen ink, and fountain pen ink, as well as stamp and facsimile ink and typewriter ink have the highest level of adhesion to dactyloscopic foils, unlike the inks used in printing and for computer printers, where there is no

5 Similar to the reflection of a face in the mirror.

6 By using the options such as Image-Rotate Canvas-Flip Canvas Horizontal.

7 A thousandth part of a millimeter.

Nowa Kodyfikacja Prawa Karnego 49, 2018

(C) for this edition by CNS 
adhesion or it is of a low level. However, the practice has shown that this is not always the case, at least when it comes to lines written on the paper with the ballpoint pens. One can only guess the reason for this, especially when the age of the document or its preservation conditions are unknown.

The following examples from the practice illustrate this phenomenon, since in the first case (Example 1) reflection of lines written with ballpoint pen filled with aniline ink appears in the print on an adhesive layer of white gelatine foil, and in the second case (Example 2), it does not appear.

Example 1. Crossing lines of a signature written with a ballpoint pen and printed line of similar color. A reflection of lines written with a ballpoint pen filled with aniline ink has appeared in the print on an adhesive layer of gelatin foil

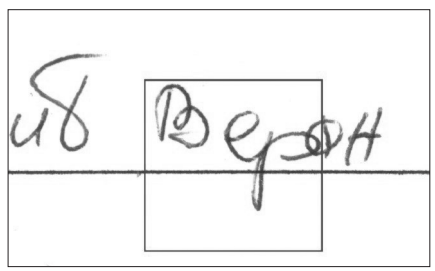

Picture 1.1. The intersection of a blue ballpoint pen ${ }^{8}$

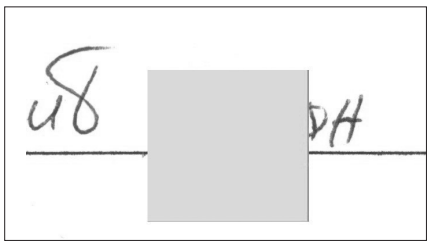

Picture 1.2. The position of a piece of a white pen line and black line for the signature in the text. Dactyloscopic foil over the crossed lines in a document before its exposure to the pressure of consecutive hammer blows of light intensity

${ }^{8}$ All the illustrations in the paper come from the final court verdicts from the court practice of the expert Miroslav Busarčević.

Nowa Kodyfikacja Prawa Karnego 49, 2018

(C) for this edition by CNS 


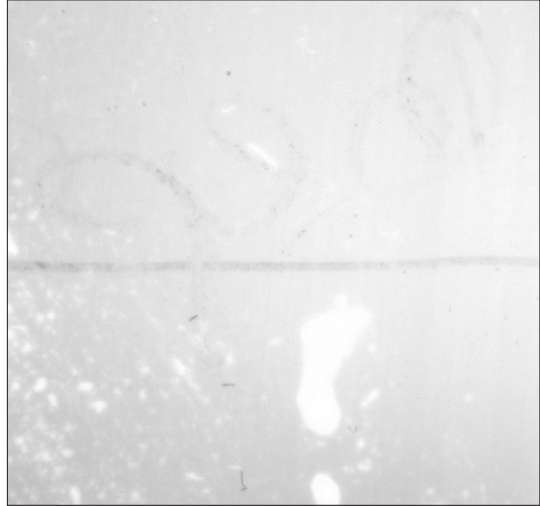

Picture 1.3. The print of crossed lines on white

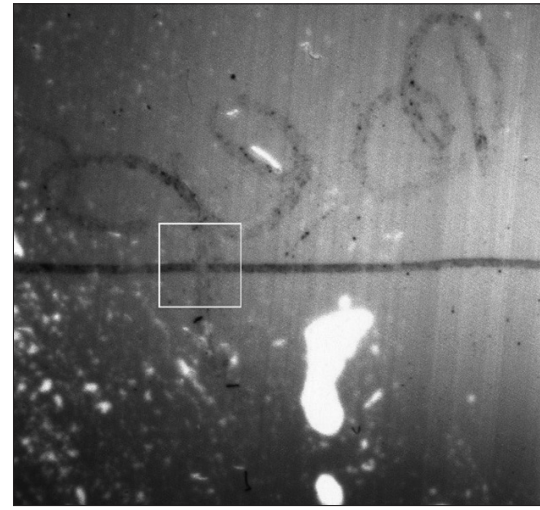

Picture 1.4. The same print (negative) after the dactyloscopic foil - negative of crossed lines visualization in Adobe Photoshop: signature before its visualization in Adobe Photoshop. The line is intersecting the printed line

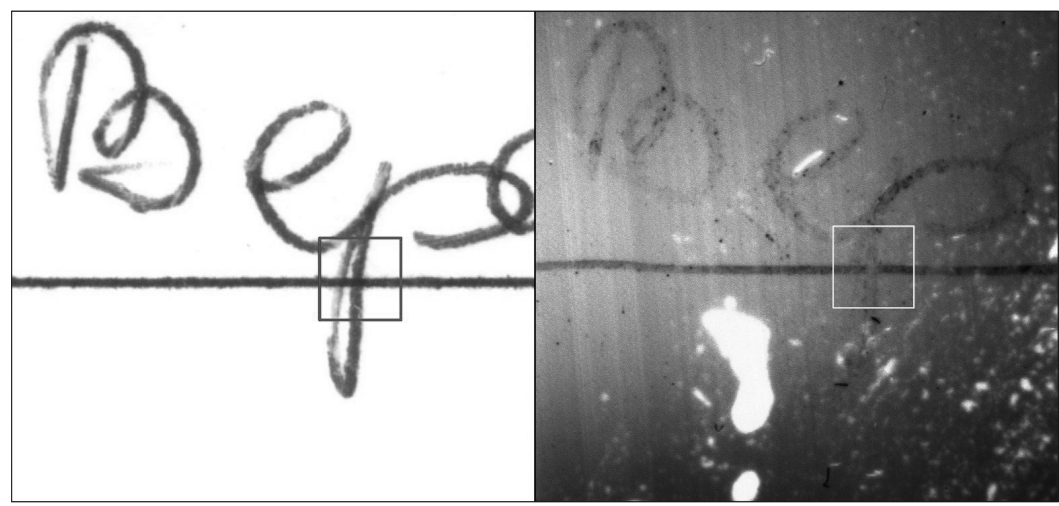

Picture 1.5. Comparative images of the intersection of a signature line and a printed line in a document and their visualized print transformed into positive: in the print signature the line is over the printed line which implies that the signature is made after printing 
Example 2. The crossing lines of a signature made with ballpoint pen and the print of a stamp of similar color. A reflection of lines written with a ballpoint pen has not appeared in the print on an adhesive layer of gelatin foil even though the pen was filled with aniline ink

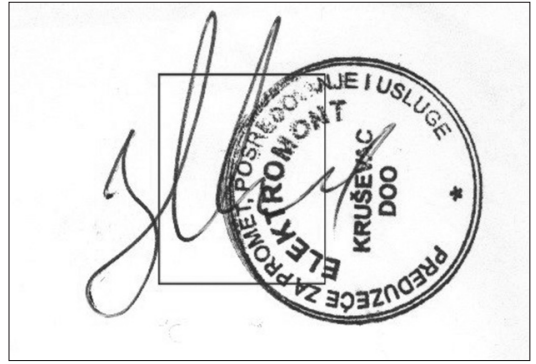

Picture 2.1. The intersection of the signature lines made by ballpoint pen and the stamp print in the document: the rectangle marks the surface of the document from which the print is lifted using a piece of white dactyloscopic foil

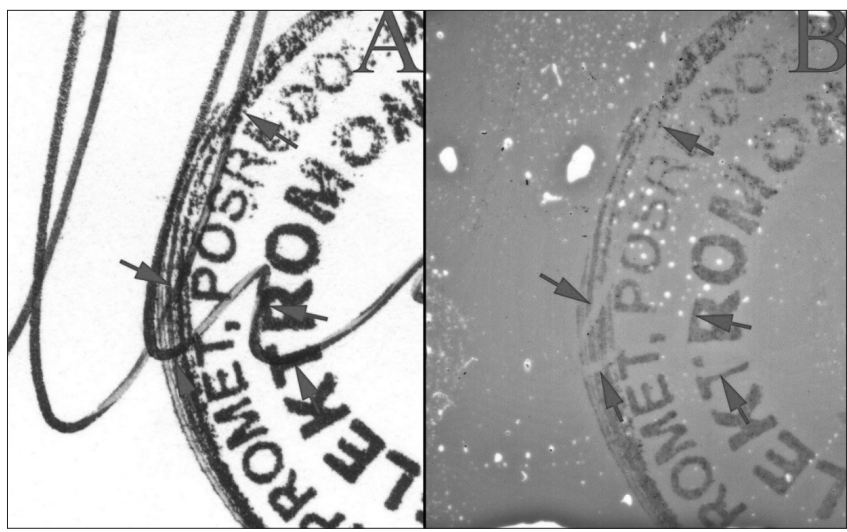

Picture 2.2. The intersection of a signature line and a stamp print in a document (A) and the visualization of the print on the foil transformed into positive (B): there are empty spaces in the stamp mark, which stand in place of unreflected lines made with a ballpoint pen, which intersect the reflected lines of the circles and the letters of the stamp mark 


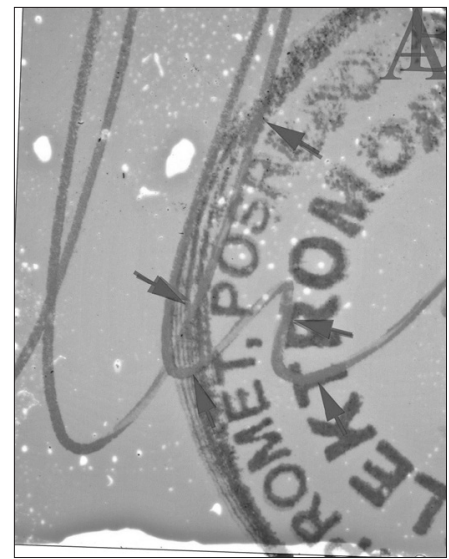

Picture 2.3. The visualization of the print on the foil, transformed into positive, over the crossed lines of the signature and the stamp print in the document, with opacity of $30 \%$ and proportion scale of 1:1. The signature line intersects the lines of the circles on the stamp print, which implies that the stamp was pressed before the signature was written

However, the difference in the level of adhesion of different materials to dactyloscopic foil, whether they were applied by writing, printing or pressing, significantly contributes to the range of application of this method, especially in the cases when the lines of written text intersect the signature lines or the lines of a stamp or a seal, even when they are of the same color. This only helps in determining the order of lines' crossing in a document, that is, identifying the intersecting lines.

The documents which are several decades old represent the exception where the application of this method was proved to be inefficient, although that does not mean that it should be abandoned altogether.

This method of expert analysis is, as well as the other analysis methods, applied only on original documents. Its application proved to be the most successful in the cases when the analyzed documents are not old and when there is a visible difference in the color of crossed lines, especially when they are made with different writing istruments. Those are the cases when the text or signature lines made with ballpoint pen, fountain pen or felt tip pen or facsimile intersect the lines of stamp or seal print or lines of the text (letters, lines and/or punctuation marks) made with the printer or the typewriter. 
Positive results can also be achieved if there is no visible difference in the color of crossed lines in the cases when the lines of stamp and seal prints or the text or signature made with ballpoint pen, fountain pen, fell tip pen or facsimile intersect the lines of the text (letters, lines and/or punctuation marks) of a computer printer. The reason for this lies in the already mentioned difference of their adhesion level to the adhesive layer of dactyloscopic foil.

However, if the crossed lines are made at the same time with the same substance (for example ink), and they are of the same color, positive results can not be obtained using this method.

Examples 3 and 4 from practice can serve as an illustration of the application of the described method of expert analysis of crossed lines.

\section{Example 3. The crossing lines of printed letters and a stamp print}

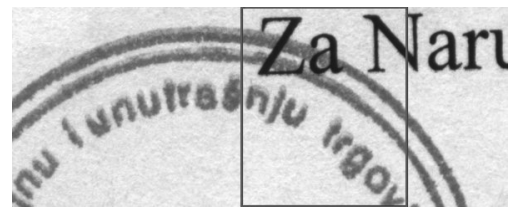

Picture 3.1. An intersection of a stamp print and the letters of a printed text: the rectangle marks the surface of the document from which the print was lifted with the piece of white dactyloscopic foil under the pressure of consecutive hammer blows of light intensity

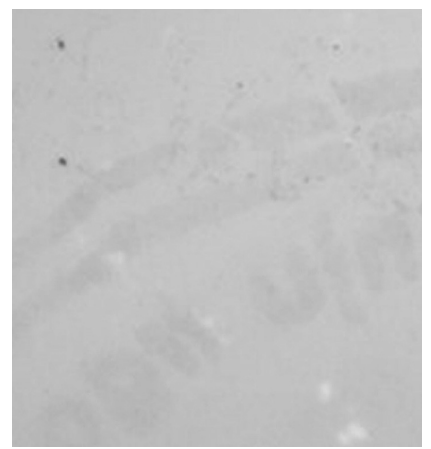

Picture 3.2. The print of the crossed lines

Nowa Kodyfikacja Prawa Karnego 49, 2018

(C) for this edition by CNS 


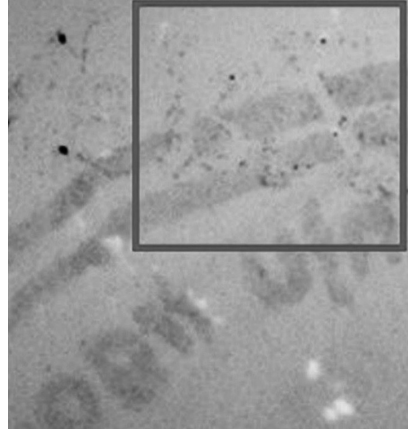

Picture 3.3. The same print (negative) after the dactyloscopic foil - negative of crossed lines visualization in Adobe Photoshop: the rectangle before the visualization in Adobe Photoshop marks the place of intersection of the unreflected printed letters and (reflected) lines of the circles and the letters of the stamp print
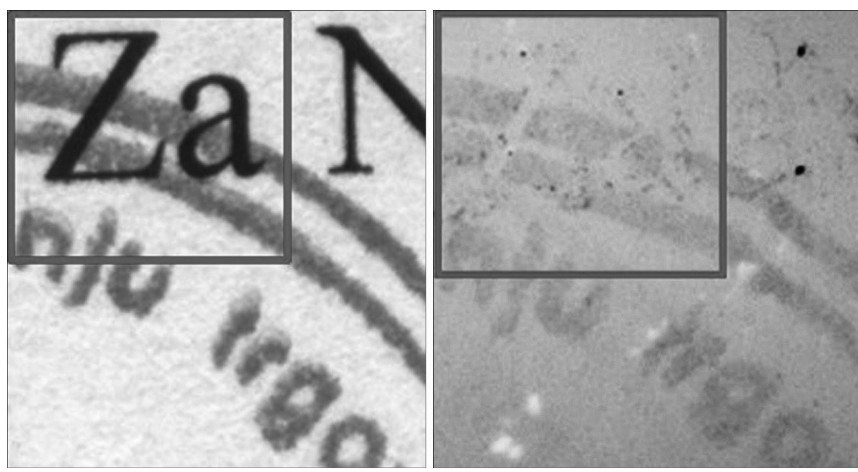

Picture 3.4. Comparative images of the intersection of printed text's letters and stamp print in a document and their visualized print transformed into positive: in the print there are empty parts which stand in the place of unreflected lines of printed text which intersect reflected lines of the seal print's circle 


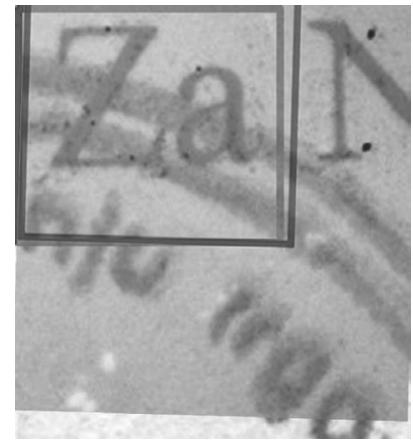

Picture 3.5. The visualization of the print, transformed into positive, across the crossed lines of the printed text and the stamp print in the document with the opacity of $30 \%$ and the proportion scale of $1: 1$. The lines of the printed letters are over the lines of the circles of the stamp print, which implies that the stamp was made before the text was printed

Example 4. Were the signature and stamp print made after the text had been printed or was the text printed after the signature and the stamp print had been made on a blank memorandum of a company?

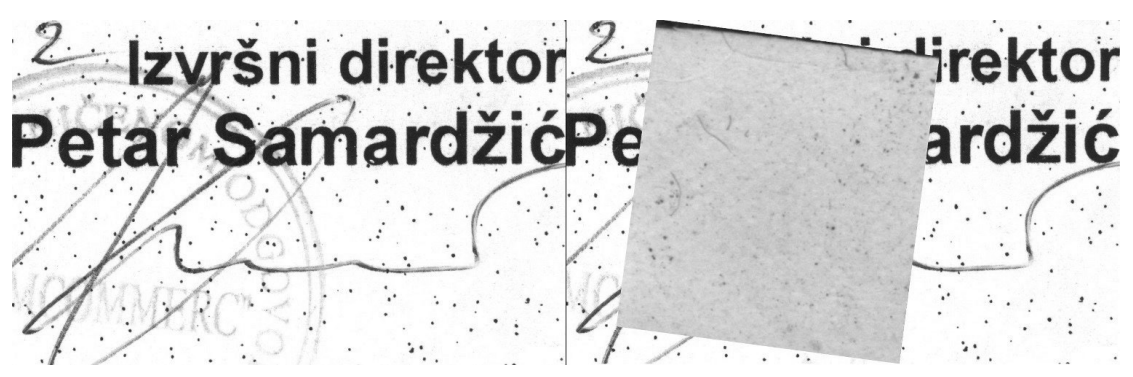

Picture 4.1. The crossed lines of the printed letters, the signature written with ballpoint pen and the stamp print in the document, and the position of the applied piece of white dactyloscopic foil on the document (after the hammer blows) 


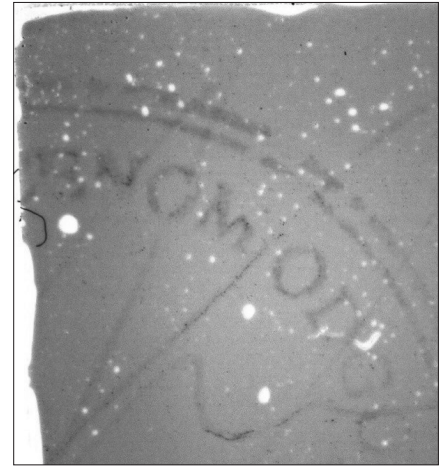

Picture 4.2. The visualization of the transformed into positive: the empty parts of the unreflected lines of the printed letters intersect the reflected signature lines and the stamp print

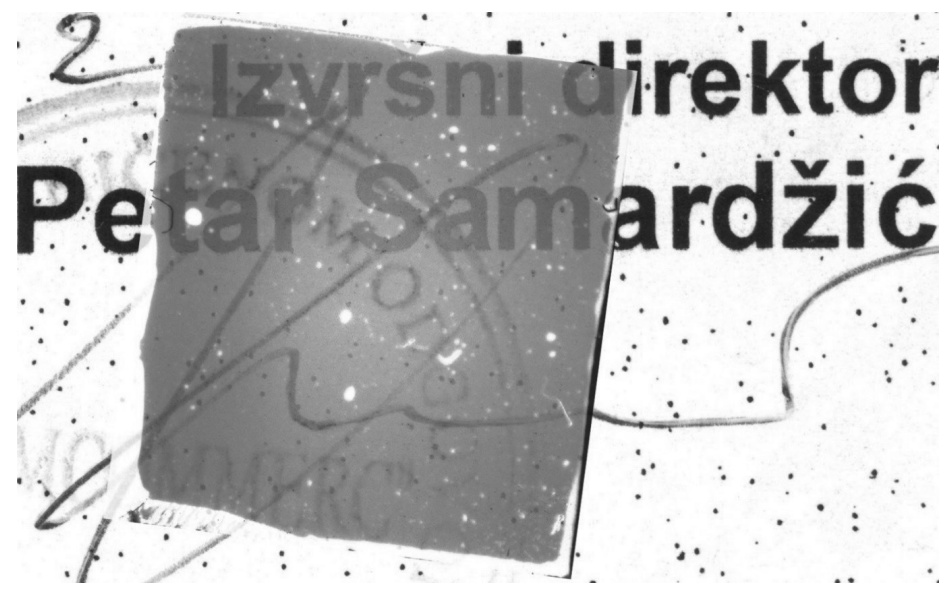

Picture 4.3. The visualization of the print, transformed into positive, over the crossed lines in the document with the opacity of $10 \%$ and the proportion scale of $1: 1$. The printed letters are over the signature and the stamp print, which implies that the signature and the stamp print were made before the text of the document was printed 
This method has an incredibly wide range of application. However, all forensic experts should conduct their own experiments of different cases before applying it, so that they can be certain that it is properly applied and that it is successful.

\section{Conclusion}

This method is empirical, replicable and available to all forensic experts because it does not require any laboratory equipment or devices, apart from a scanner and personal computer with the Adobe Photoshop program. Its advantage is the simplicity of the procedure and the range of application spectrum. Even though the method is invasive, the changes are visible only on the level of microscopic details of crossing lines and do not affect their appearance.

\section{References}

Aleksić Ž. (1996), The Expert Analysis of the Forged Documents, Handwriting and Counterfeiting, Savremena administracija, Belgrade.

Bojko K., Roux C., and Reedy B.J. (2008), "An examination of the sequence of intersecting lines using attenuated total reflectance-Fourier transform infrared spectral imaging", Journal of Forensic Sciences 53(6), pp. 1458-1467.

Daéid N.N., Whitehead L., and Allen M. (2008), "Examining the effects of paper type, pen type, writing pressure and angle of intersection on white and dark dominance in ESDA impressions of sequenced strokes - An application of the likelihood ratio", Forensic Science International 181(1-3), pp. 32-35.

Day S.P., Ellen D., and Davies C. (2005), Scientific Examination of Documents: Methods and Techniques, CRC Press, Boca Raton-London-New York.

e Brito L.R., Martins A.R., Braz A., Chaves A.B., Braga J.W., and Pimentel M.F. (2017), "Critical review and trends in forensic investigations of crossing ink lines", $\operatorname{Tr} A C$ Trends in Analytical Chemistry 94, pp. 54-69.

Giles A. (1993), "Extending ESDA's capability: The determination of the order of writing and impressions using the technique of electrostatic detection", Forensic Science International 59(2), pp. 163-168.

Godown L. (1963), "Sequence of writings", Journal of Crimal Law and Criminology 54, pp. 101-109.

INTERPOL's Counterfeit Currency and Security Documents Branch and International Academy of Experts in Handwriting and Documents Research Project "Physicalchemical Study of Crossed Lines Intersection” (2017), https://www.interpol.int/ 
Crime-areas/Financial-crime/Counterfeit-currency-and-security-documents/Research-projects (accessed: 22.03.2017).

Jasuja O.P., Singla A.K., and Chattopadhyay P.K. (1987), "A simple method for determining the sequence of intersecting ball pen lines", Journal of the Forensic Science Society 27(4), pp. 227-230.

Koons R.D. (1985), "Sequencing of intersecting lines by combined lifting process and scanning electron microscopy", Forensic Science International 27(4), pp. 261-276.

Maksimović R., Bošković M., Todorić U. (1990), The Methods of Physics, Chemistry and Physical Chemistry Applied in Criminalistics, The Academy of Criminalistic and Police Studies, Belgrade.

Oron M., and Tamir V. (1979), "Development of SEM methods for solving forensic problems encountered in handwritten and printed documents", International Criminal Police Review 32, no. 4, pp. 24-30.

Radley R. (1995), "Determination of sequence of intersecting ESDA impressions and porous tip, fibre tip and rollerball pen inks", Science and Justice 35(4), pp. 267-272.

Simonović L. (1956), The Expert Analysis of Documents in Criminalistics, Ministry of Internal Affairs of the Republic of Serbia, Belgrade.

Singla A.K., Jasuja O.P., and Kaur, J. (1994), "Determining the sequence of intersecting ball-pen lines and correctable carbon ribbon strokes", Forensic Science International 64(2-3), pp. 141-145.

Strach S.J. (1978), "Establishing the sequence of intersecting ball-point pen strokes", Forensic Science 11(1), pp. 67-74.

Vaid B.A., Rana R.S., and Dhawan, C. (2011), "Determination of sequence of strokes through reflection spectra", Problems of Forensic Science 87, pp. 193-203.

Waeschle P. A. (1979), "Examination of line crossings by scanning electron microscopy", Journal of Forensic Science, 24(3), pp. 569-578.

\section{Summary}

This paper presents the method of crossed lines expert analysis developed and applied in Serbia and other countries in the region by Miroslav Busarčević, a court expert with a degree in physical chemistry and MSc in criminalistics. The authors of the paper explain the procedure of lifting the prints of crossed lines using gelatin dactyloscopic foils, the scanning and visualization of the obtained print in the Adobe Photoshop computer program; presentation and interpretation of the results.

Keywords: crossed lines, gelatin dactyloscopic foils, pressure (hammer blow), lifting techniques, Photoshop. 